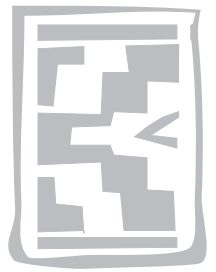

\title{
Production trials involving use of the FAMACHAO system for haemonchosis in sheep: preliminary results
}

\author{
J.A. VAN WYK* \\ Department of Veterinary Tropical Diseases, Faculty of Veterinary Science, University of Pretoria \\ Private Bag X04, Onderstepoort, 0110 South Africa
}

\begin{abstract}
VAN WYK, J.A. 2008 Production trials involving use of the FAMACHAC system for haemonchosis in sheep: preliminary results. Onderstepoort Journal of Veterinary Research, 75:331-345

In three trials conducted on two separate farms the production of sheep treated for naturally acquired haemonchosis using the FAMACHAC system of targeted selective treatment (TST) (i.e. to treat only those animals unable to manage unaided in the face of heavy Haemonchus challenge) was compared to that of suppressively drenched sheep in the same flock. As expected by the research team who developed and evaluated the FAMACHAC system, TST did result in some loss in production. However, despite high levels of worm challenge in two of the trials and the fact that the comparison was with suppressive drenching which is not sustainable, the total effect was relatively small in relation to the important advantage of using the TST as regards reduced selection for anthelmintic resistance (AR).

Concerning the sustainability of worm control, it is concluded that the development of drug resistance to anthelmintics leaves sheep and goat farmers in South Africa no choice but to use methods of TST such as FAMACHAC. The FAMACHAC system can also be a useful clinical aid for early on-farm detection of AR by farmers; the degree of improvement in the colour of the ocular mucous membrane from pale to red in individually drenched anaemic animals over a period of 7-14 days can give a good indication of the efficacy of the compound(s) used.
\end{abstract}

Keywords: Animal production, body condition scoring, FAMACHAC, haemonchosis, sheep, targeted selective treatment

\section{INTRODUCTION}

Anthelmintic resistance, a global threat for grazing animal production (Van Wyk, Malan \& Bath 1997a; Waller 1997), is arguably worse in small ruminants in South Africa than in most other countries (Van Wyk, Stenson, Van der Merwe, Vorster \& Viljoen 1999). For instance, this is the first country where a population of Haemonchus contortus was reported to be resistant to drugs of all five of the anthelmintic activity groups available for controlling this worm

\footnotetext{
* E-mail: jan.vanwyk@up.ac.za

Accepted for publication 22 August 2008-Editor
}

species (Van Wyk, Malan \& Randles 1997b). Other firsts are worm populations shown to be resistant to rafoxanide (Van Wyk, Malan, Gerber \& Alves 1987), closantel (Van Wyk, Gerber \& Alves 1982), ivermectin (Carmichael, Visser, Schneider \& Soll 1987; Van Wyk \& Malan 1988), disophenol and nitroxynil (Van Wyk et al. 1997b).

Against this background of severe anthelmintic resistance (AR) and the fact that anthelmintics are a sine qua non for profitable sheep and goat production, South African helminthologists developed a novel method of targeted selective treatment (TST) based on on-farm clinical evaluation of the colour of the ocular mucous membranes of sheep and goats, 
in order to identify and treat only those animals unable to cope unaided with a Haemonchus challenge. After it had been shown that it was possible to characterise the anaemia of haemonchosis in this way (Malan \& Van Wyk 1992; Malan, Van Wyk \& Wessels 2001), the method was developed into the FAMACHAC system (Bath, Malan \& Van Wyk 1996; Van Wyk \& Bath 2002), which is being used in several countries (Sotomaior, Milczewski, Morais \& Schwartz 2003; Kaplan, Burke, Terrill, Miller, Getz, Mobini, Valencia, Williams, Williamson, Larsen \& Vatta 2004; Molento, Tasca, Gallo, Ferreira, Bononi \& Stecca 2004).

According to preliminary results the FAMACHAC system, which from the nature of the test is of use for haematophagous worm species only, can be complemented by the use of body condition scoring/score (BCS) and Dag scoring (Van Wyk \& Riley, unpublished 2008; Van Wyk \& Bath 2002).

An important consideration is that, in addition to the value in relation to reduction of selection for $A R$, the FAMACHAC system can be used in practice as a clinical method of evaluation of the continued efficacy of anthelmintics being used from time to time. If anaemic animals are marked at the time that they are treated and then re-evaluated a week later, there should be at least one FAMACHAC category more red in colour than before. Based on results reported by Malan et al. (2001) and while taking into consideration that animals with critical levels of anaemia often do not recover despite effective anthelmintic treatment (J.A. van Wyk, unpublished observations 1980), severely anaemic sheep should improve by two FAMACHAC categories within 7 days.

\section{Validation of the FAMACHAC system}

Validation trials have been conducted on a variety of farms in South Africa and the Americas to evaluate numerous aspects of field application of the FAMACHAC system. Some of the trials have continued for more than 5 years (Van Wyk \& Bath 2002). In the process it was shown that most sheep under severe $H$. contortus challenge required no, or only one treatment over a full summer season (Malan et al. 2001; Van Wyk \& Bath 2002), while a small minority (mostly $<10 \%$ ) needed more than two treatments. In other words, the vast majority of sheep could cope with no, or only one treatment, and the FAMACHAC system proved to be effective for identifying the stragglers which were unable to manage without being dewormed. Only very few trainees were unable to implement the FAMACHAC system successfully, and the level of success appeared to be independent of the level of literacy of the persons concerned (Van Wyk \& Bath 2002). In a questionnaire survey in which opinions were gauged through multiple questions in six categories (including practicability, animal production, financial aspects and usefulness), the system was rated very highly ( $\geq 80 \%$ ) by almost all farmers, farm workers and veterinarians, who had been involved in the field testing of the system. Their combined estimate was a reduction in outlay on anthelmintics of approximately $58 \%$ (Bath \& Van Wyk 2001; Van Wyk \& Bath 2002). Preliminary results have also shown the heritability of clinical evaluations with the FAMACHAC system to be on a par with both haematocrit (the gold standard used for validation of FAMACHAC results) and faecal worm egg counts (FECs) (Bisset, Van Wyk, Bath, Morris, Stenson \& Malan 2001; Van Wyk \& Bath 2002; Van Wyk \& Riley, unpublished 2008). The main benefits of the system are the reduction in treatments, its use for discriminating between animals of varying ability to cope with infection (thus allowing genetic selection), and through the phenomenon of refugia (i.e. leaving animals in every flock or herd untreated to ensure relatively high levels of unselected worms in refugia on pasture [Van Wyk 2001]) to lower selection pressure on $H$. contortus for AR.

This paper concerns an important aspect that has previously not been included in validation trials on FAMACHAC applicability, namely the effect on production of leaving many animals undrenched when all are exposed to high levels of Haemonchus challenge. Three production trials were conducted on two farms over the Haemonchus season which lasts more or less from October/November to April/May in South Africa, with the peak Haemonchus challenge commonly occurring in January or February.

\section{GENERAL MATERIALS AND METHODS}

\section{Pasture}

The grazing on both farms on which the three trials were conducted consists of natural, predominantly grassland pasture in a series of different paddocks which were alternated according to available herbage, with the sheep returning to each paddock at intervals of about 3-5 weeks during the rainy season. The pastures were shared in rotation with other flocks which were not included in the trials.

\section{Trial plans}

Because differences in nutrition are generally more important than worm infection as concerns the pro- 
duction of grazing ruminants, it is essential that trials for comparing worm management strategies are done in such a way that the levels of nutrition are practically identical between trial groups. This, however, is well-nigh impossible to achieve if separate pastures are used for different treatment groups, unless it is possible to include numerous replicates on relatively uniform pasture, e.g. by subdividing a single pasture into numerous paddocks, to ensure similar conditions per paddock as regards slope, vegetation type and stance of herbage in all of them (Leathwick, Miller, Atkinson, Haack, Alexander, Oliver, Waghorn, Potter \& Sutherland 2006a; Leathwick, Waghorn, Miller, Atkinson, Haack \& Oliver 2006b). As a result of a combination of factors, including generally low grazing pressure per unit area of the natural pastures concerned and thus relatively large paddocks with concomitant problems regarding differences in slope and pasture composition (e.g. in proportion of grasses/edible shrubs per paddock), it is seldom practical to follow the above approach in South Africa. Hence it was decided despite obvious limitations, to conduct each of the production trials using different trial groups grazing together on common pasture.

In each trial a group of suppressively treated sheep (all drenched at intervals short enough practically to prevent development of worms to adulthood in the animals) was compared primarily with another similar group drenched according to the FAMACHAC system, i.e. only when judged to be anaemic, whether borderline or severe (see below). The various trial groups ran together in a single flock on common pasture per trial.

\section{Allocation of sheep to trial groups}

Because of distances of 300 and $250 \mathrm{~km}$, respectively, by road from the laboratory, the farmers concerned had to perform the random allocation of the sheep to trial groups according to the following method. The available animals were placed in a race and, starting from the front, the first animal of each pair was allocated to one trial group and the second to the other group, with the sequence alternated per consecutive pair.

\section{TST evaluation}

The persons who applied the FAMACHAC and BCS systems on the two farms were pre-trained and evaluated as described by Van Wyk, Bath, Groeneveld, Stenson \& Malan (2001a). At intervals mostly varying from 7-35 days (Table 1) during the peak of the Haemonchus season (November to March, inclusive) each trial sheep was classed into the applicable FAMACHAC colour categories, by comparison with a colour chart (Van Wyk \& Bath 2002) with the categories varying from 1 (red, non-anaemic mucous membranes), through progressively paling shades of pink (categories 2-4), to practically white (category 5). BCS evaluation was done, according to Cottle (1991), on a scale from 1 (extremely emaciated) to 5 (very obese), in steps of either a quarter of a category (Farm 1), or half a category (Farm 2).

Faecal worm egg counts were done at irregular intervals, using a sucrose flotation modification of the McMaster method (Reinecke 1973), at a sensitivity of 100 eggs per gram of faeces.

TABLE 1 Trial plans

\begin{tabular}{|c|c|c|c|}
\hline \multirow{2}{*}{ Particulars } & \multicolumn{3}{|l|}{ Trial } \\
\hline & 1 & 2 & 3 \\
\hline $\begin{array}{l}\text { Farm } \\
\text { Flock - type } \\
\quad-\text { size } \\
\text { Trial sheep } \\
\text { Age } \quad \text { - flock } \\
\quad-\text { trial sheep } \\
\text { Trial groups } \\
\text { Evaluation intervals } \\
\text { Peak-season drench for alld }\end{array}$ & $\begin{array}{l}1 \\
\text { Stud } \\
\pm 180 \text { rams }+48 \text { wethers } \\
48 \text { wethers } \\
6-8 \text { months } \\
6-8 \text { months } \\
2^{a} \\
7-31 \text { days }^{b} \\
\text { Yes }\end{array}$ & $\begin{array}{l}1 \\
\text { Stud } \\
\pm 180 \text { ewes } \\
\text { All the ewes } \\
6-8 \text { months } \\
6-8 \text { months } \\
3^{\text {b }} \\
10-31 \text { days } \\
\text { Yes }\end{array}$ & $\begin{array}{l}2 \\
\text { Commercial } \\
\pm 400 \text { ewes } \\
98 \text { ewes } \\
\text { Adult } \\
10-12 \text { months } \\
2^{\text {a }} \\
7-35 \text { days }^{c} \\
\text { No }\end{array}$ \\
\hline
\end{tabular}

a Suppressively treated group (all treated on every occasion) and TST group (only individuals treated when judged anaemic with the FAMACHAC system)

b The TST group was nominally divided into two subgroups which were treated identically, with the exception that one (TSTmonitor subgroup) was periodically sampled for FECs and the other not

c One interval after the drench at the peak of the Haemonchus season was 78 days

d Whether all sheep were drenched at the peak of the Haemonchus season 
Production trials involving FAMACHAC system for haemonchosis in sheep: preliminary results

\section{Drenching in relation to FAMACHAC}

Unless otherwise indicated, in all three trials the groups of sheep in the FAMACHAC-treated groups were drenched only if judged by clinical evaluation to be in FAMACHAC categories 3,4 or 5 .

\section{Statistical evaluation}

Linear models were fitted to the data and the hypothesis of equal treatment group effects was tested (SAS Inst. Inc., Cary, NC, USA). Comparisons between time periods were made using repeated measures analysis.

TABLE 2 Experiment 1 (Farm 1, wethers in replacement ram flock): Mean FECs per group of sheep, plus dates on which all groups were drenched

\begin{tabular}{|c|c|c|c|c|}
\hline \multirow{2}{*}{ Date } & \multicolumn{2}{|c|}{ Mean FECs ${ }^{a}$} & \multicolumn{2}{|c|}{ Group drenching particulars ${ }^{b}$} \\
\hline & TST & Suppressive & Group & Interval (days) \\
\hline $07 \mathrm{Nov}$ & 756 & 236 & Both (7 Nov) & $\mathrm{n} / \mathrm{a}$ \\
\hline $17 \mathrm{Nov}$ & 75 & 78 & - & - \\
\hline $27 \mathrm{Nov}$ & 216 & 157 & Suppressed (30 Nov) & 23 \\
\hline $8 \mathrm{Dec}$ & 757 & 169 & - & - \\
\hline $18 \mathrm{Dec}$ & 301 & 370 & Suppressed (18 Dec) & 8 \\
\hline 12 Jan & 3795 & 17 & Suppressed (8 Jan) & 21 \\
\hline 29 Jan & 8452 & 728 & Suppressed (19 Jan) & 11 \\
\hline $19 \mathrm{Feb}$ & 15112 & 288 & Suppressed (19 Feb) & 31 \\
\hline $12 \mathrm{Mar}$ & 0 & 4 & Both (8 Mar) & 16 \\
\hline $22 \mathrm{Mar}$ & 67 & 0 & - & - \\
\hline $3 \mathrm{Apr}$ & 283 & 125 & Both (9 Apr) & 32 \\
\hline $23 \mathrm{Apr}$ & 158 & 46 & - & - \\
\hline 14 May & 295 & 260 & - & - \\
\hline 4 Jun & 1683 & 2142 & Both (4 Jun) & 56 \\
\hline 27 Jun & 83 & 50 & - & - \\
\hline
\end{tabular}

a Eggs $\mathrm{g}^{-1}$ of faeces

b Shifted to the closest date for which FECs were available n/a Not applicable

TABLE 3 Experiment 1 (Farm 1, wethers in replacement ram flock): Highest individual FECs of the TST-treated group of sheep

\begin{tabular}{|c|c|c|c|c|c|c|}
\hline \multirow{2}{*}{ Date } & \multicolumn{5}{|c|}{ Sheep $(n)$ in different high egg count ranges } & \multirow{2}{*}{$\begin{array}{l}\text { Total }>4000 \\
\text { FEC }\end{array}$} \\
\hline & $4000-5900$ & $6000-8900$ & $9000-11900$ & $12000-19900$ & $>20000$ & \\
\hline 18 Des & 2 & 4 & 0 & 0 & 0 & 6 \\
\hline 12 Jan & 3 & 5 & 0 & 0 & 0 & 8 \\
\hline 23 Jan & 2 & 2 & 2 & 2 & 0 & 8 \\
\hline 29 Jan & 3 & 2 & 5 & 3 & 2 & 15 \\
\hline $19 \mathrm{Feb}$ & 1 & 1 & 3 & 9 & 5 & 19 \\
\hline Total & 11 & 14 & 10 & 14 & 7 & 56 \\
\hline
\end{tabular}

TABLE 4 Farm 1: Anthelmintic restistance reversion using the principle of genetic dilution (Van Wyk \& Van Schalkwyk 1990)

\begin{tabular}{|l|l|l|l|}
\hline \multirow{2}{*}{ Anthelmintic } & \multicolumn{2}{|l|}{ Anthelmintic efficacy (\%) } & \multicolumn{2}{|c|}{ After (ewe) } \\
\cline { 2 - 4 } & Before & After (lamb) & 91.6 \\
\hline Albendazole & 0 & 75.1 & 88.0 \\
Ivermectin & 30.7 & 96.5 & 96.9 \\
Rafoxanide & 76.7 & 95.8 & 97.9 \\
Levamisole & 73.8 & 97.1 & \\
\hline
\end{tabular}

a Van Wyk et al. 2001b 


\section{EXPERIMENT 1 (FARM 1): REPLACEMENT RAM FLOCK}

\section{Materials and methods}

While $H$. contortus is the predominant gastrointestinal nematode of small ruminants on this farm belonging to a Merino stud breeder, at times bankruptworm (Trichostrongylus colubriformis) and brown stomach-worm(Ostertagia/Teladorsagiacircumcincta) occur in sufficiently large numbers to cause periodic production losses. It is situated on the Highveld of Mpumalanga, and the predominantly summer rainfall it receives is relatively evenly distributed, resulting in ideal conditions for the development of Haemonchus sp. during the trial period.
The flock of sheep that was available for the trial consisted of replacement rams (Table 1) being prepared for "conventional" Best Linear Unbiased Prediction (BLUP) analysis (growth, wool production and characteristics) some months after conclusion of the trial. Hence, since it was not feasible randomly to select a suppressively treated group from the flock, which would then not be eligible for BLUP analysis, 48 wethers from a single flock of similar age to the rams, were introduced in October into the flock of rams and were dewormed at the beginning of November. The wethers were then randomly allocated to two groups, each of 24 animals. While all the animals in the suppressively treated group were routinely treated with levamisole on the dates indicated in Table 2, the other group as well as the rams
FIG. 1

Experiment 1 (Farm 1, wethers in replacement ram flock): Mean body mass

FIG. 2

Experiment 1 (Farm 1, wethers in replacement ram flock): Mean body condition score
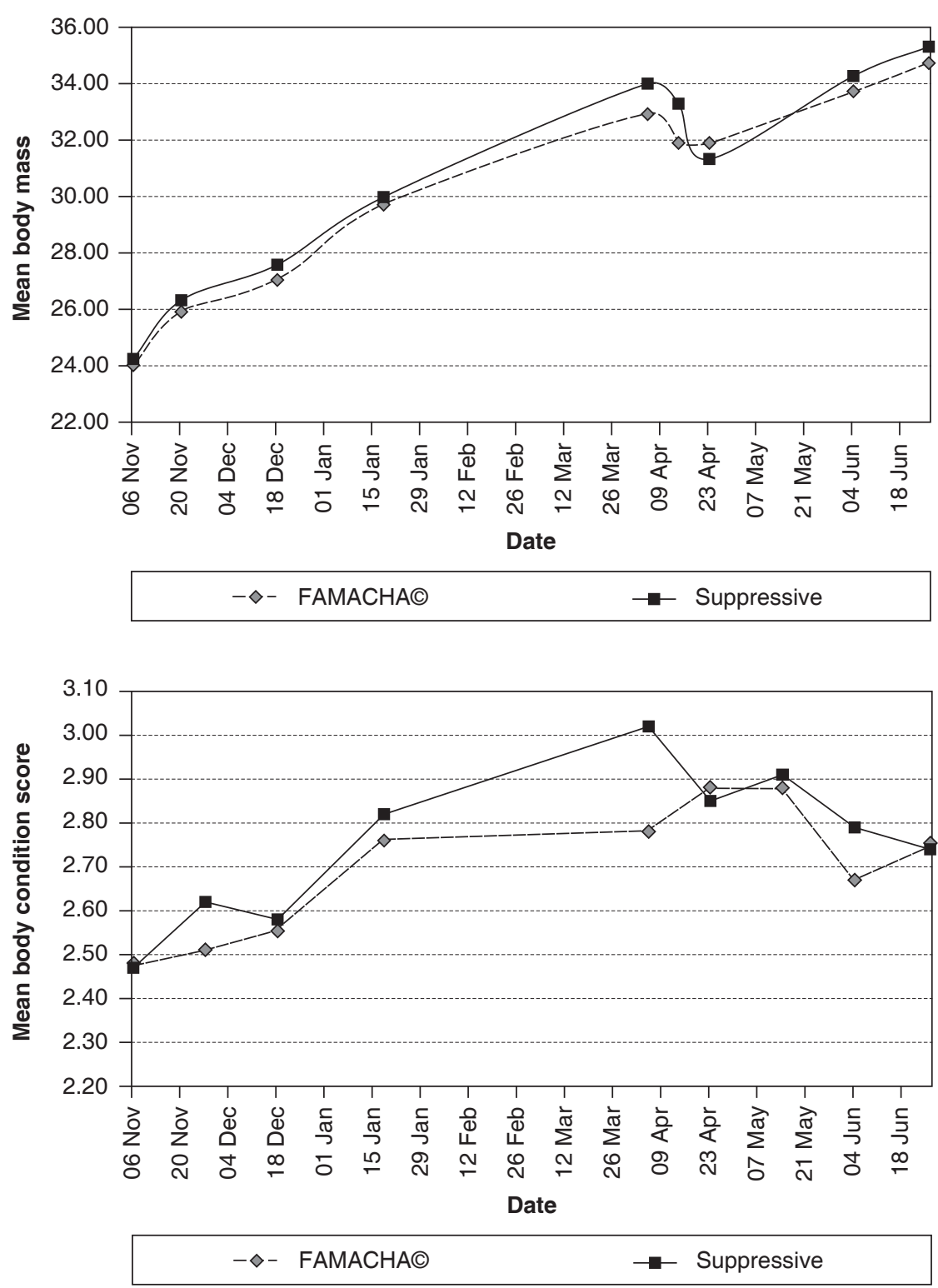
Production trials involving FAMACHAC system for haemonchosis in sheep: preliminary results

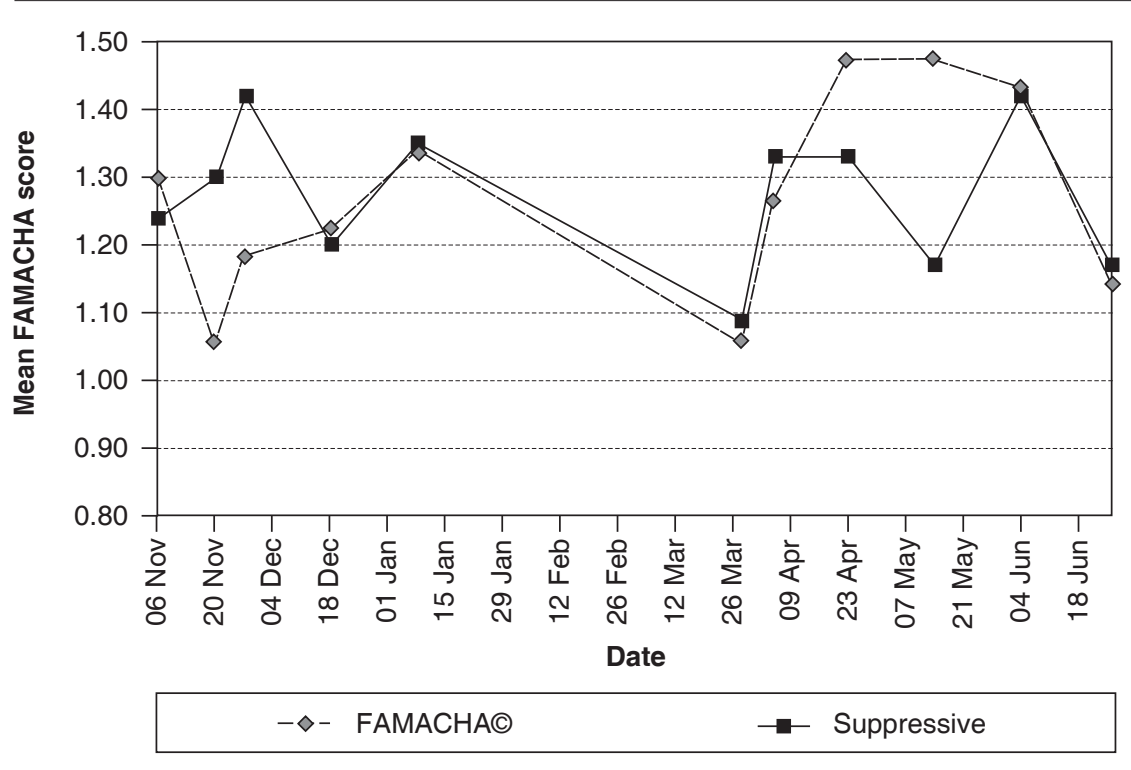

FIG. 3

Experiment 1 (Farm 1, wethers in replacement ram flock): Mean FAMACHAC score were drenched (with the same compound) only if they were clinically evaluated to be in FAMACHAC categories 3,4 or 5 . The suppressive treatment, as well as FAMACHAC and BCS were done at irregular intervals between 30 November and 19 February, when the rams were mustered for weighing. On the latter date all the sheep were dewormed to end the heritability testing of the rams for helminth resistance/resilience and thenceforth the wethers in both trial groups and the rams were target drenched until 4 June (Table 2).

\section{Results}

The results are summarised in Tables 2-4 and Fig. $1-3$. While the mean FECs of the FAMACHAC group rose from 75 after the initial blanket treatment on November to a maximum of more than 15000 on 19 February, that of the Suppressive group varied between 78 and 728 during this period. From Table 3 it can be seen that relatively large proportions of the wethers in the FAMACHAC group had extremely high FECs between 23 January and 19 February. Differential larval counts indicated overwhelming numbers of Haemonchus sp., but Trichostrongylus sp. and Ostertagia/Teladorsagia sp. were present in small percentages at all times excepting at the peak of the Haemonchus season, when they were virtually absent, probably because they were swamped proportionally by Haemonchus sp. (Miller, Waghorn, Leathwick \& Gilmour 2006).

None of the differences in body mass and BCSs between the two trial groups was statistically significant $(P>0.05)$. In the case of the FAMACHAC evaluations the largest differences did not occur when
FECs were at their maximum, but rather before and after the period of peak worm challenge, with significant differences $(P<0.01)$ during January and February.

\section{Comment}

The $H$. contortus worms on Farm 1 were previously extremely resistant to compounds from all the available activity groups. In an initial FEC reduction test conducted in 1995, the efficacy of albendazole, rafoxanide, ivermectin and levamisole (drenched as representative of the benzimidazole, salicylanilide, macrocyclic lactone and imidazothiazole activity groups, respectively) varied from $0-76 \%$ (Table 4). However, using the technique of genetic dilution developed by Van Wyk \& Van Schalkwyk (1990), the population was largely reverted to susceptibility by artificial introduction of susceptible $H$. contortus infective larvae, to the extent that the variation after the dilution varied from $75.1 \%$ for albendazole to $97.9 \%$ for levamisole in the case of lambs, and from $88.0 \%$ for ivermectin to $97.9 \%$ for levamisole in the case of ewes (Table 4) (Van Wyk, Van Wijk, Stenson \& Barnard 2001b).

Despite the dramatic differences in the FECs of the two trial groups of wethers, their body masses and BCSs closely followed one another, with no statistically significant differences between the groups $(P>$ 0.05 ). The maximum differences in mean values between the groups were less than $1.5 \mathrm{~kg}$ in the case of body mass, and also less than a quarter of a category for BCS. Interestingly, the maximum differences of both body mass and BCS between the groups occurred at the beginning of April, at a time 
TABLE 5 Experiment 2 (Farm 1, young replacement ewes): Mean FECs per group

\begin{tabular}{|l|l|c|}
\hline \multirow{2}{*}{ Date } & \multicolumn{2}{|l|}{ FECs } \\
\cline { 2 - 3 } & TST & Suppressive \\
\hline 11 November & 1665 & 2687 \\
7 January & 7748 & 13 \\
17 January & 3458 & 14 \\
3 February & 4180 & - \\
8 February & 1552 & 133 \\
9 April & 369 & 691 \\
25 April & 29 & 33 \\
\hline
\end{tabular}

TABLE 6 Experiment 2 (Farm 1, young replacement ewes): Breakdown of FECs of TST trial groups (both subjected to the FAMACHAC system) combined $(n=142)$, at the peak of the Haemonchus season

\begin{tabular}{|c|l|l|}
\hline \multirow{2}{*}{ Worm egg count } & Sheep & \multicolumn{2}{|l|}{} \\
\cline { 2 - 3 } & $\boldsymbol{n}$ & $\%$ \\
\hline$>15000$ & 25 & 18 \\
$9000-14900$ & 34 & 25 \\
$5000-8900$ & 24 & 17 \\
$3000-4900$ & 21 & 15 \\
$<3000$ & 34 & 25 \\
\hline
\end{tabular}

when FECs of both groups were at low levels. Similarly, the trends in FAMACHAC scores are difficult to evaluate in relation to the high FECs, in that the largest differences in the mean FAMACHAC scores occurred during periods when there were relatively small differences in FECs.

The egg counts in the Suppressive group, although low, were almost always positive, indicative of some drug resistance on the farm, but some of the drenching intervals were longer than the 21 day prepatent period of $H$. contortus. On the other hand, judging from the results of Experiment 3, it is unlikely that the levels of infection signified by these low FECs of this trial group would have had an appreciable effect on the production of the sheep concerned.

Although also dewormed according to the FAMACHAC system of TST, the rams could not contribute to the null hypothesis tested, that TST applied with the help of the FAMACHAC system, would not affect the production of the animals. However, being young and susceptible to infection, they did serve the purpose of ensuring dynamic cycling of $H$. contortus on the pasture, thus also ensuring that the wethers were challenged with the levels of $H$. contortus infection to be expected on pasture grazed by such a group of susceptible animals.
The suppressive treatments and FAMACHAC evaluations per treatment of anaemic sheep in the trial were carried out irregularly because the treatments had largely to fit in with the management routine of the farmer concerned. Because it was not practicable for the farmer to examine the animals more often, the periods between FAMACHAC evaluation of the sheep (Table 2) were considerably longer at the peak of the Haemonchus season than weekly, as recommended by the developers of the FAMACHAC system (Van Wyk \& Bath 2002).

\section{EXPERIMENT 2 (FARM 1)}

\section{Materials and methods}

\section{Animals}

A second flock of sheep comprising replacement ewes of much the same age as the rams and wethers in Trial 1 was available for the second trial on Farm 1 (Table 1). The ewes had been weaned a few months previously and were similarly being prepared for BLUP analysis over the trial period. However, despite this fact, 25 of them were withdrawn from BLUP evaluation to serve as suppressively dewormed "worm-free" production controls (Suppressive group) for the rest of the animals (Table 1). In order to reduce the labour requirements in the trial, the TST group was subdivided into a TST-monitor and a TST-rest subgroup, of which only the former subgroup was routinely sampled for faecal worm egg counting, excepting at the peak of the Haemonchus season, when all the sheep were sampled for FECs and haematocrit determinations, and all the sheep in every trial group were dewormed. For the rest of the trial after the peak worm Haemonchus season drench mentioned, all the groups of sheep were treated according to the FAMACHAC system, only when judged to be in FAMACHAC categories 3, 4 or 5.

The intervals between clinical evaluation and weighing of the sheep varied from 12-32 days at the peak of the Haemonchus season, instead of 7 days, as suggested by Van Wyk \& Bath (2002).

\section{Results}

The results are summarised in Tables 5-6 and Fig. 4-6.

\section{FECs per gram of faeces}

The FECs of the ewes indicated an extremely high level of infection (Table 2). Of the 25 ewes which 


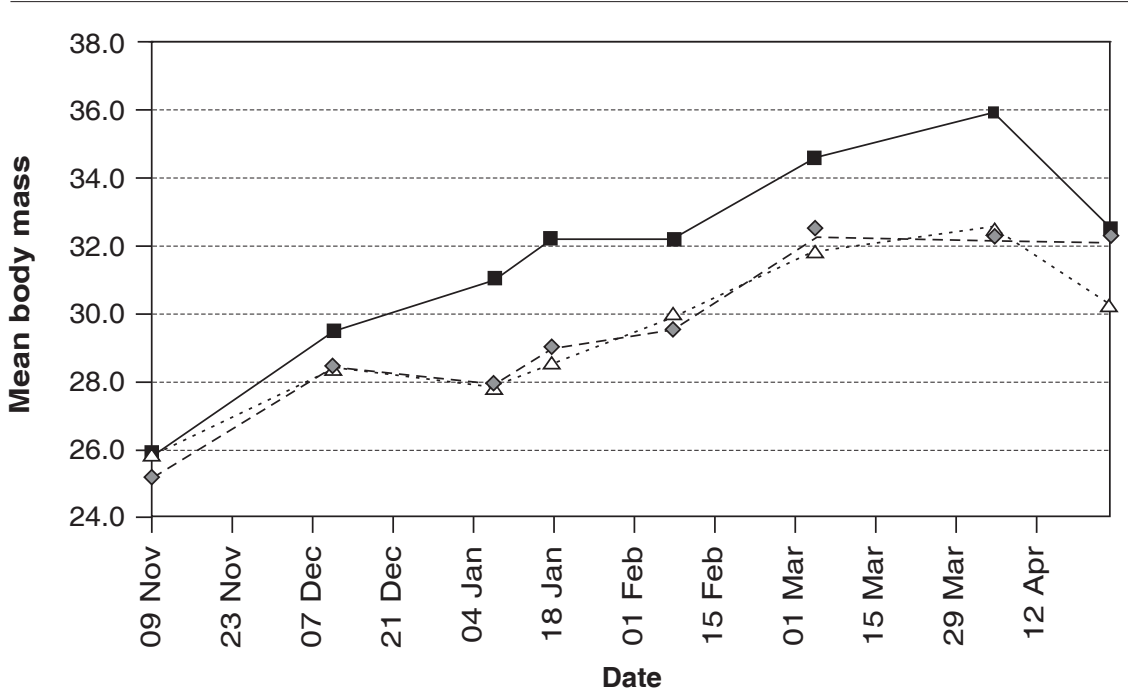

$\diamond-$-Flock $\quad$ Suppressive $\quad$-.-.FAMACHAC

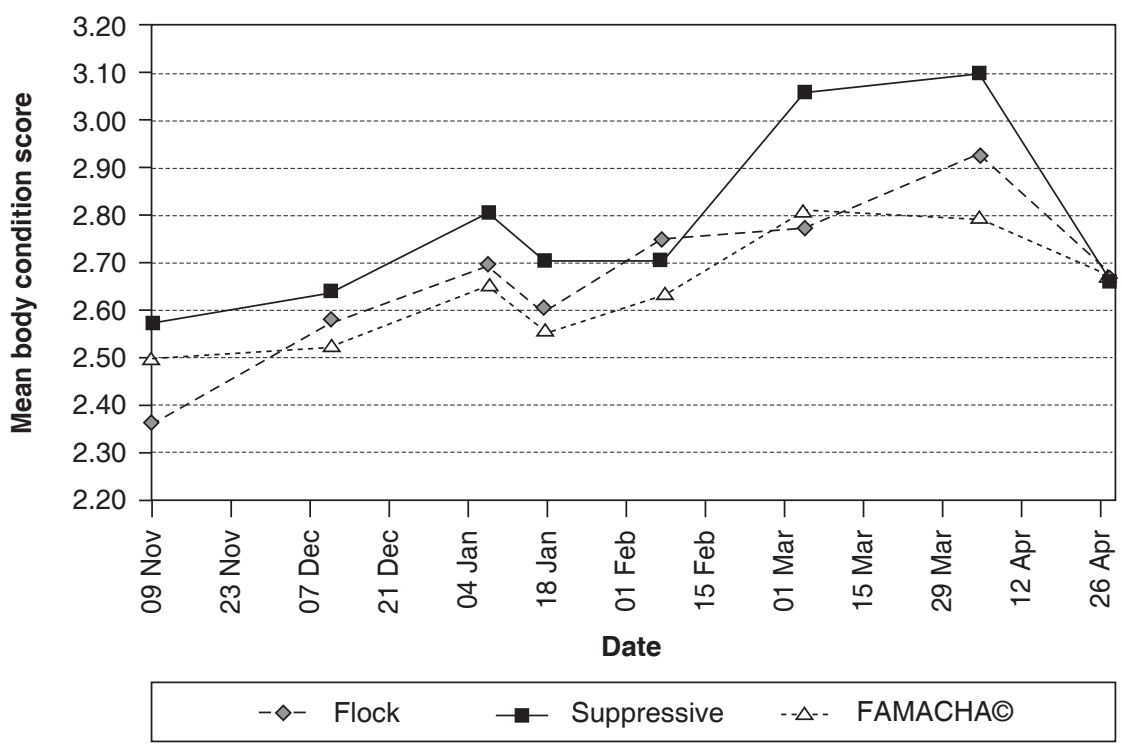

FIG. 4

Experiment 2 (Farm 1, young replacement ewes): Mean live body mass

FIG. 5

Experiment 2 (Farm 1, young replacement ewes): Mean BCS had faecal egg counts higher than 15000 , five had counts exceeding 30000 , with a maximum of 38000 in one of the sheep.

\section{Mean sheep body mass (Fig. 4)}

From the third sampling occasion onward, significant differences $(P<0.05)$ occurred, with the sheep in the Suppressive (i.e. practically worm-free) group being significantly heavier than those in the two other groups, excepting on the last sampling occasion, when the difference in mass between the Suppressive and TST-rest groups was not significant $(P>0.05)$. The masses of the two TST subgroups ran practically in parallel until the fifth sampling occasion $(P<0.05)$ when the differences between the two were significant $(P<0.04)$. By the end of the trial, however, the differences between the TST-rest subgroup and the Suppressive group were not statistically significant $(P>0.05)$. At the final sampling occasion the TST-monitor subgroup was a mean of $2.2 \mathrm{~kg}$ (i.e. about $1 \mathrm{~kg}$ of meat) lighter than the other two groups. The maximum difference in live body mass at the peak of the worm season was close to $4 \mathrm{~kg}$.

\section{Mean BCS (Fig. 5)}

These scores followed very similar trends to those of the mean body mass of the sheep (Fig. 5), excepting that growth rate was apparently more sensitive than BCS for indicating adverse conditions. In addi- 


\section{FIG. 6}

Experiment 2 (Farm 1, young replacement ewes): Mean

FAMACHAC score

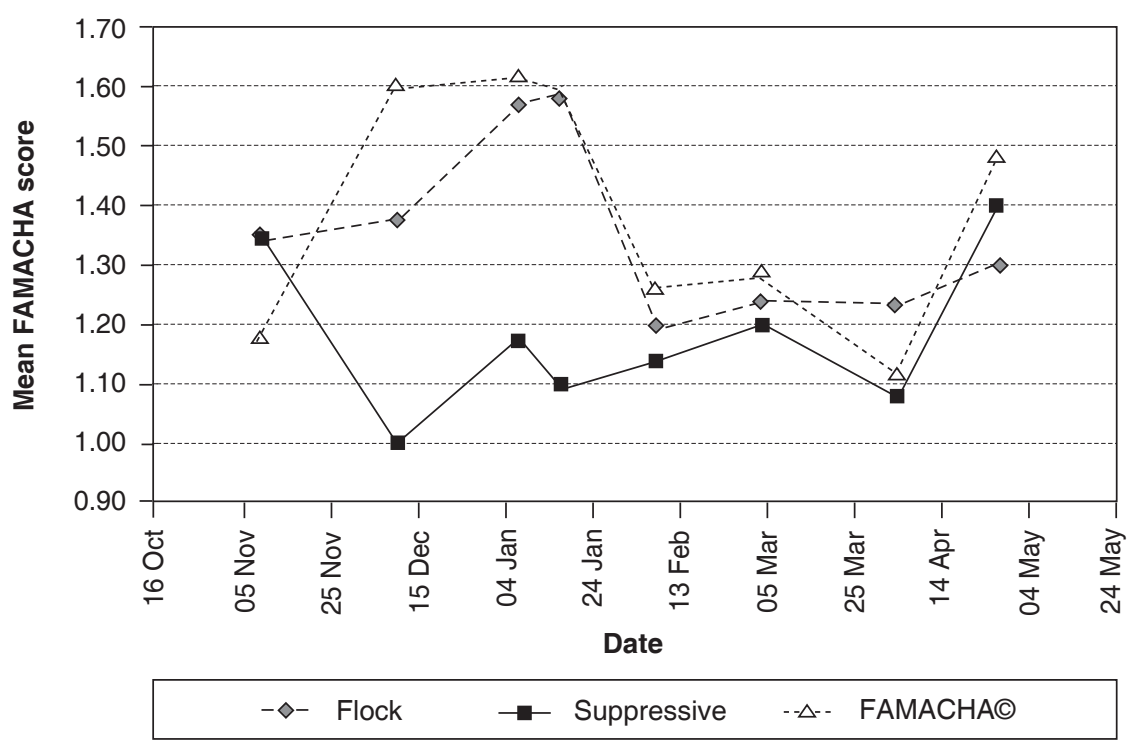

tion, in contrast to growth, it was only at the sixth sampling occasion, on 4 March, that significant differences were noted between the Suppressive and the TST groups, with the suppressive treatment group differing significantly from the other two groups $(P<0.002)$, which did not differ significantly from one another at any stage $(P>0.7)$.

\section{FAMACHA@ score (Fig. 6)}

As was to be expected from the high FECs, the groups subjected to targeted treatment became highly significantly more anaemic than the Suppressive group, until 17 January, when all the animals were treated. Thereafter, the scores of all groups followed a similar trend with non-significant differences occurring between the groups until the end of the trial $(P>0.05)$. As in the case of BCS and in contrast to body mass, the differences in mean FAMACHAC values between the TST-rest and TST-monitor subgroups of the FAMACHAC group were not statistically significant at any stage during the trial $(P>$ 0.1 ).

\section{Comment}

It should be borne in mind that, as in Trial 1, all the sheep in the trial were dewormed at the peak of the Haemonchus season. Had this not been done it is probable that greater differences between selectively and suppressive sheep would have occurred. Similarly, worm resistance on the farm led to less than complete efficacy of the anthelmintics used against the helminths of the Suppressive group (Table 5) and this would have favoured the Null Hypoth- esis that the FAMACHAC system does not cause production losses in the animals. On the other hand, as discussed below, the FAMACHAC system was not applied optimally on Farm 1, but had this been done, it is conceivable that the differences in production would have been smaller.

No explanation can be offered for the fact that the TST-monitor and TST-rest subgroups differed statistically at the end of the study since both subgroups ran in the same flock and were drenched according to the same rules, namely only when evaluated to be in FAMACHAC categories $3-5$. It seems unlikely that the mere difference of periodically sampling one and not the other subgroup, would have been responsible for this difference.

\section{EXPERIMENT 3 (FARM 2)}

\section{Materials and methods}

The farm, situated in the eastern Free State, has natural pastures, the composition of which is similar to that on Farm 1. The terrain is, however, more hilly and the average rainfall is lower and usually more erratic.

\section{Animals}

A flock of approximately 400 commercial Merino breeding ewes, including newly introduced young replacement ewes, was available for testing the production effect of FAMACHAC. Ninety-six of the replacement ewes were randomly allocated to two groups, 48 animals each, of which one was the Sup- 
Production trials involving FAMACHAC system for haemonchosis in sheep: preliminary results

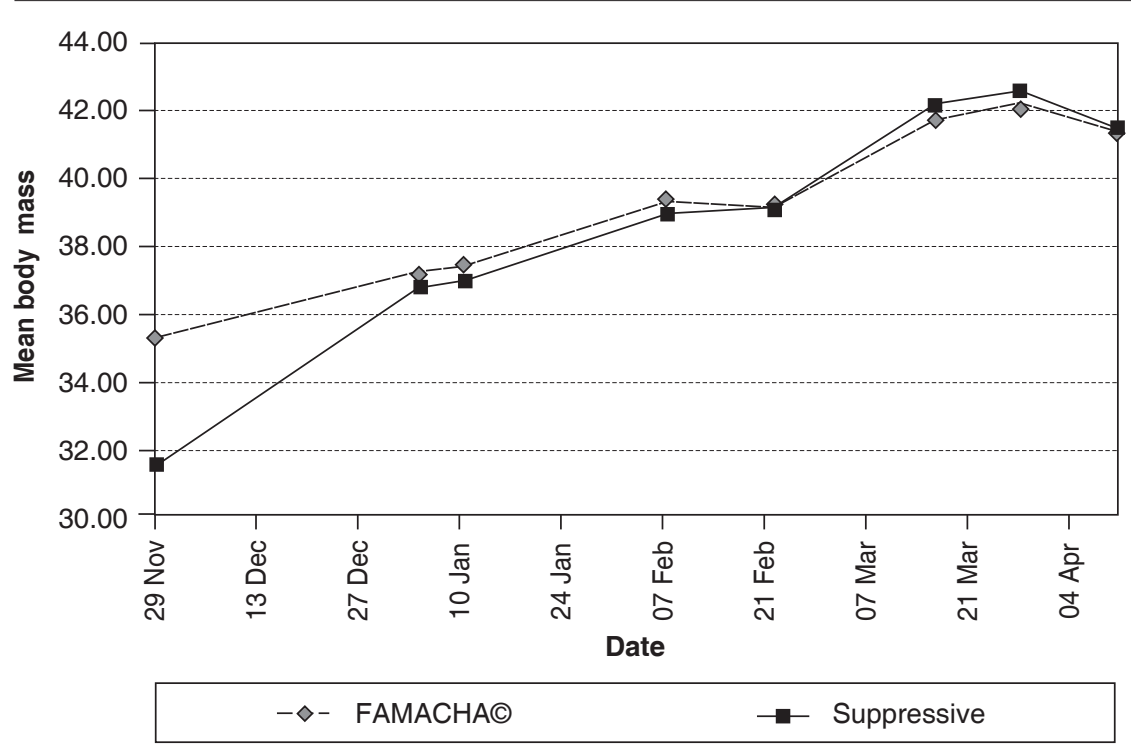

FIG. 7

Experiment 3 (Farm 2, young replacement ewes): Mean live body mass

FIG. 8

Experiment 3 (Farm 2, young replacement ewes): Mean BCS

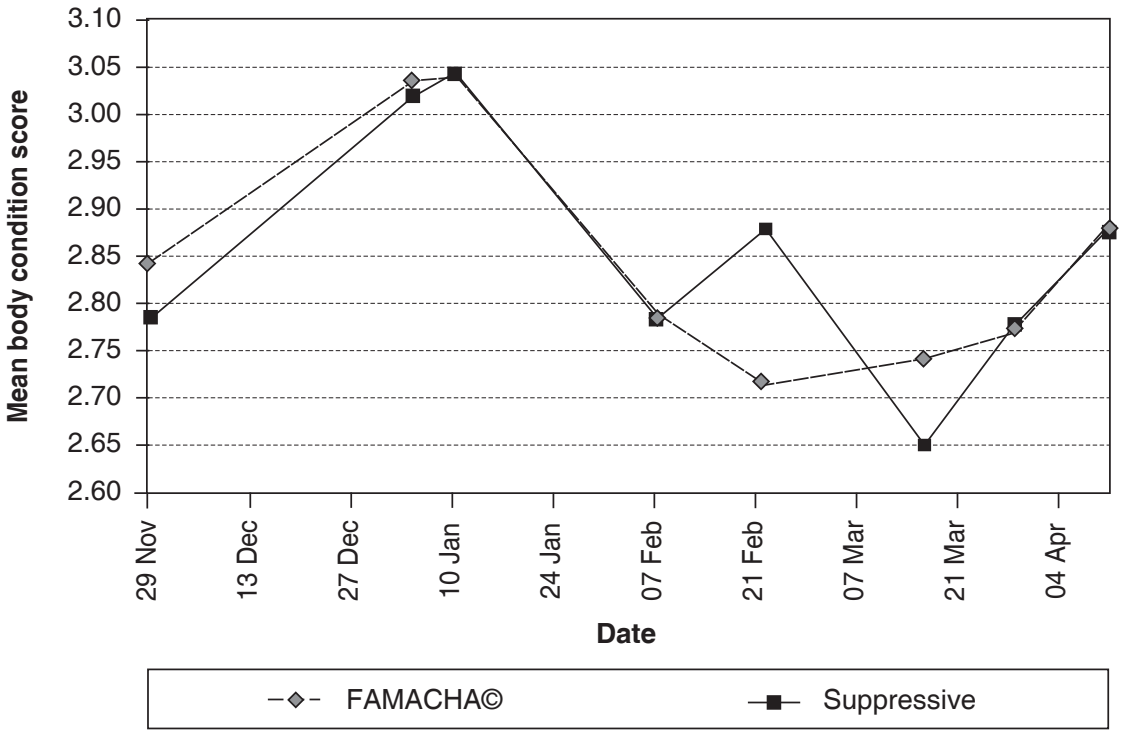

TABLE 7 Experiment 3 (Farm 2, young replacement ewes): FECs of TST-monitor and Suppressive trial groups ( $n=48$ per group)

\begin{tabular}{|l|l|l|}
\hline \multirow{2}{*}{ Date } & \multicolumn{2}{|l|}{ FECs } \\
\cline { 2 - 3 } & FAMACHAC & Suppressive \\
\hline 10 January & 3300 & 0 \\
27 February & 2086 & 0 \\
10 April & 600 & 3 \\
15 May & 700 & 58 \\
\hline
\end{tabular}

a No FECs were done at the start of the trial

pressive group for which the aim was more or less to exclude worms as a factor in their production. The sheep in the other group, as well as those in the rest of the flock, were subjected to worm manage-
TABLE 8 Experiment 3 (Farm 2, young replacement ewes): Largest individual FECs (January and February)eggs per gram of faeces

\begin{tabular}{|l|l|}
\hline FEC & Sheep $(\boldsymbol{n})$ \\
\hline$>9000$ & 2 \\
$6000-8900$ & 3 \\
$4000-5900$ & 6 \\
\hline \multicolumn{2}{|l|}{ Maximum count (10 January): 15400 FEC } \\
\hline
\end{tabular}

ment by the FAMACHAC system. The animals in the two trial groups were weighed periodically and their condition evaluated by BCS. In contrast to the two trials on Farm 1, the FAMACHAC group was 


\section{FIG. 9}

Experiment 3 (Farm 2, young replacement ewes): Mean FAMACHAC score

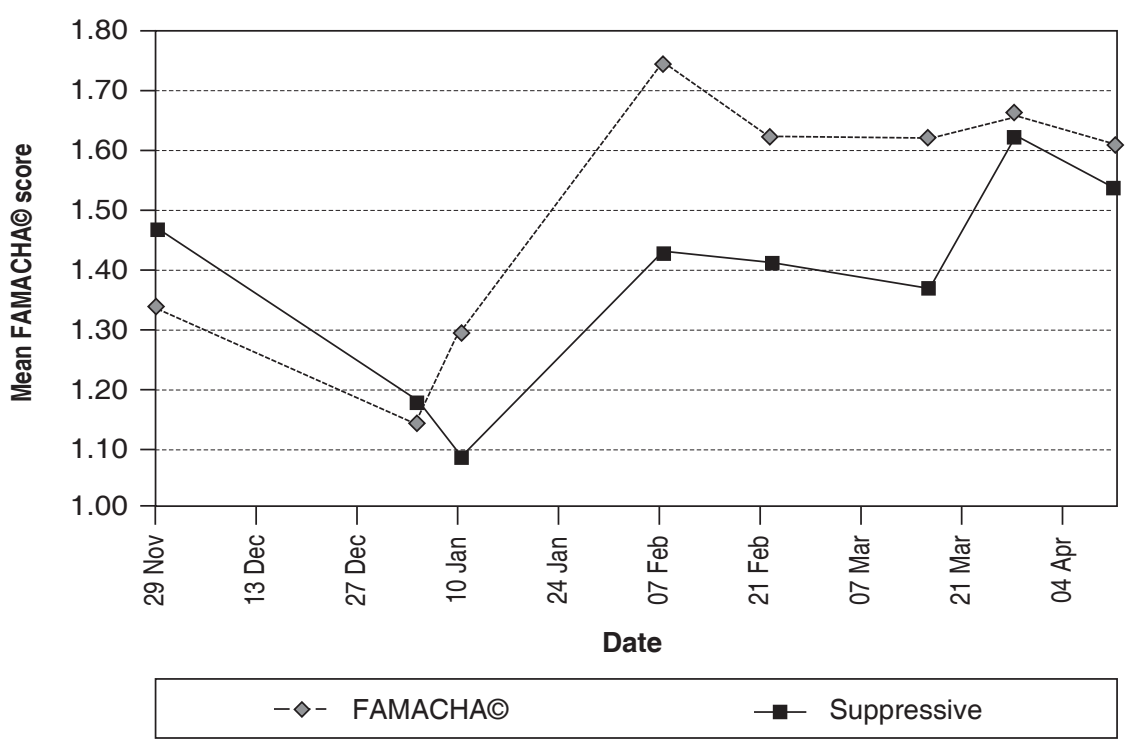

not dewormed in toto at the peak of the Haemonchus season.

\section{Results}

The results are summarised in Tables $7-8$ and Fig. 7-9.

\section{FECs}

Except at the sampling occasion 5 months into the trial, the sheep of the Suppressive group had extremely low FECs after the initial drench (Table 7). In contrast, some of the sheep in the FAMACHAC group developed counts of more than 6000 during January and February, with a maximum count of $15400 \mathrm{~g}^{-1}$ of faeces in one of them (Table 8).

\section{Live body mass}

After an initial mean difference of $3.3 \mathrm{~kg}$, the mean body mass of the two trial groups ran practically parallel and close to one another for the rest of the trial. With the exception of the first sampling occasion on November 29, which was the beginning of the Haemonchus season $(P<0.003)$, no statistically significant differences occurred between the groups $(P>$ 0.4). However, when the statistical comparisons were calculated using the initial body mass per group as covariant, the differences between groups were all similarly highly significant $(P<0.002)$.

\section{BCS}

Similar to the body mass, mean BCS results of the two trial groups closely paralleled one another, with the exception of two occasions (February and March) when they diverged to some extent, with the scores of the Suppressive group being once above and once below those of the FAMACHAC group. Of these two deviations, only the one of 21 February was statistically significant $(P<0.003)$ (Fig. 8). However, in contrast to body mass, mean BCSs differed by only 0.07 of a category at the commencement of the trial on 29 November $(P>0.2)$. This provides some support to accepting that it is unlikely that there was bias in the allocation of the sheep to the trial groups and that the farmer hence had failed to follow the instructions laid down for randomisation.

\section{FAMACHA@ score}

After non-significant differences in mean scores at both the first and last two sampling occasions $(P>$ $0.05)$, the two trial groups did differ significantly $(P<$ 0.01 ) on the four occasions during the peak Haemonchus season, i.e. between 10 January and 18 March, inclusive.

\section{Comment}

The unfortunate, highly significant, initial difference between the two trial groups $(P<0.003)$ complicates evaluation of the results of Experiment 3. The FECs of the sheep subjected to the FAMACHAC system were considerably lower in this experiment than in the corresponding animals in Experiment 2 (Tables 5-6). However, the mean count of the FAMACHAC group, at $3300 \mathrm{eggs} \mathrm{g}^{-1}$ of faeces (with a maximum count of 15000 in one of the sheep) on 10 January (Table 8) indicates that deaths of sheep could have been expected, had the most anaemic sheep not been drenched during the course of the trial. The 
reason for the initial, highly significant difference in the body mass of the two trial groups of animals can only be speculated about. The most obvious deduction would be that the farmer was biased towards selecting lighter sheep for suppressive treatment for better profitability, and hence had failed strictly to follow the agreed-upon method of randomisation. But the fact that the mean body masses of the two groups were practically identical throughout the period of peak worm challenge and thereafter until the end of the trial, and that neither the FAMACHAO nor the BCSs differed significantly at the start of the trial, seems to indicate that the effect of targeted selective drenching must have been minimal on production, despite the fact that, as discussed further below, the comparison was with unsustainable, suppressive drenching.

\section{DISCUSSION}

Anthelmintic resistance is leaving many farmers with no choice but to abandon unsustainable conventional drenching practice and at present there seems to be no practicable sustainable alternatives to a targeted treatment approach to worm management. Sustainability of worm management has become much more of a practical than a theoretical question, particularly in sheep-producing countries (Van Wyk et al. 1997a; Waller 1997), and is rapidly including cattle production as well (Rhodes, Leathwick, Pomroy, West, Jackson, Lawrence, Moffat \& Waghorn 2006; Van Wyk, Hoste, Kaplan \& Besier 2006), which needs to be taken into consideration in discussions on alternatives to existing unsustainable worm control practices. For instance, on Farm 1 multiple AR was so severe that sheep production was under grave threat (J.A. van Wyk, unpublished observations 1997), requiring genetic dilution of the H. contortus population using an approach developed by Van Wyk \& Van Schalkwyk (1990), after which its susceptibility improved considerably, this level of efficacy apparently being maintained over the ensuing 8 years with the use of TST, based primarily on the FAMACHAC system.

Malan \& Van Wyk (1992), Bath, Malan \& Van Wyk (1996) and Van Wyk \& Bath (2002) suggested that the well-known phenomenon of over-distribution of worm burdens in host populations (Barger 1985) could be utilised for reducing selection for AR by applying a system of TST, such as FAMACHACi.e. to drench only those individual animals that are unable to manage without treatment, in contrast to blanket treatment of every animal when some of them succumb to current worm challenge. Subse- quently, supportive results have been obtained, among others by Leathwick et al. (2006a), who did not target only overly susceptible animals for treatment, but rather compared a TST group in which the $15 \%$ largest lambs were left untreated when the rest were repeatedly drenched strategically, with another group of which all the lambs were drenched on every corresponding occasion.

The effect of the FAMACHAC system on the production of animals subjected to it cannot be regarded as an all-or-nothing phenomenon; since there are five different FAMACHAC categories, the level at which it is applied can be graded in relation to the severity of Haemonchus sp. challenge. For instance, while it is being recommended that animals evaluated to be in FAMACHAC categories 3-5 be treated invariably (J.A. van Wyk, unpublished data 2005), when deemed necessary, this can be modified to include animals graded category 2 , or even all animals when rising levels of anaemia indicate that too few animals are being treated. The eventual effect on animal production will thus depend on the level of worm challenge at which treatment is applied from time to time. Also, the more frequently the animals concerned are clinically evaluated with the FAMACHAC system, the sooner severely affected animals will be detected and treated, and the less the effect on their production is likely to be.

In the present trials sheep were not treated until severely affected. The sheep in Trial 3 were treated only if microhaematocrit testing confirmed levels of $15 \%$ or lower. However, in Trials 1 and 2 treatment was based exclusively on clinical FAMACHAC evaluation and, as discussed below, subsequent data analysis showed that the animals were consistently misclassified; the actual FAMACHAC levels were mostly one category lower than those allocated by the evaluator. Hence the animals in all three trials were subjected to severe worm challenge before they were treated.

To decide on a basic trial plan for this set of trials, was difficult. Firstly, it was considered important to conduct the trials under practical farming conditions, since the FAMACHAC system comprises application by farmers themselves, mostly without the advantage of outside decision support. Secondly, a variety of factors makes it practically impossible to conduct well replicated trials under field conditions in South Africa, some of which are uneven slope, relatively extensive farming conditions with large paddocks, and difficulty in obtaining paddocks that are nutritionally similar, due to differences in the composition of grass and edible shrubs and trees. 
Nevertheless, the lack of replication is a definite shortcoming and it is essential that further trials on the effect of TST be conducted under a variety of conditions of climate and farm management.

The fact that the trial groups ran together in a single flock in each of the different trials had the disadvantage that suppressively treated animals were bound to have removed those larvae in refugia on the pastures, which could, in theory, have been available for infecting the TST-treated group, but were instead destroyed by the frequent drenching. These larvae could theoretically have accumulated to cause higher levels of challenge of the FAMACHAC-treated animals than in fact existed. However, firstly, the pasture on both farms is used optimally (i.e. not overgrazed), and therefore, as discussed by Michel (1969; 1976), grazing pressure is likely to have played a minimal role. In this managemental system the animals are withdrawn once the available pasture has been optimally utilised, with the result that the number of animals grazing per unit area is largely immaterial. In addition, the suppressively treated animals constituted only relatively small proportions of the total numbers of animals on pasture, and the fact that the pastures were shared in rotation with other flocks that were not in the trials must also be taken into consideration.

It is encouraging that the differences in production between the groups of young replacement sheep were relatively small under the conditions of severe challenge by Haemonchus sp. infection, despite the comparison with an unsustainable worm management system. In other words, it seems reasonable to deduce that, had TST been compared with the conventional programmed strategic and/or tactical drenching programmes for the region concerned, instead of with suppressive drenching, less of a production disadvantage would have resulted from the TST. The question is, however, what level of production loss would be at all acceptable to most farmers? While production loss is to be expected following the use of any system of TST (Van Wyk \& Bath 2002), the impression gained from discussions in South Africa and abroad with farmers, who are largely dependent on small ruminants production for their livelihood, is that even a marginal loss in productivity is unlikely to be acceptable to them unless $A R$ has reached the stage where there is no alternative (J.A. van Wyk, unpublished observations 2004). This is understandable if it is considered that even a loss of a few kilograms in carcase mass can be expected to have a considerable effect on the profitability of a fat lamb production system. It seems that the only solution to this impasse is optimum ap- plication of the TST systems. However, as discussed by Van Wyk (2003; 2006), TST is too complicated for farmers and even most of their advisors to apply optimally without help. Consider, for instance, that labour requirements can be considerably reduced by a variety of factors, such as by varying the FAMACHAC categories to treat from time to time over the Haemonchus season, by extending periods between evaluation of animals at times when there is relatively little worm challenge, by examining only the most susceptible classes of animals and by examining only aliquots of animals per flock instead of all of them at any given time. Van Wyk $(2003,2006)$ suggested that the only way to overcome such hurdles is to develop computerised specific decision support systems, which are so specific as to generate recommendations on the range of decisions that have to be made concerning worm management at Time $t$ on Farm $X$, in relation to the relevant factors, some of which are listed above.

BLUP analysis of data over 5 years from Farm 1 have returned much the same heritability of FAMACHAC values of sheep under heavy Haemonchus challenge, as those of FECs and haematocrit determinations (Van Wyk \& Riley, unpublished 2008). However, the FAMACHAC system has the important advantage over the other two of being based on clinical evaluation by farmers and their staff, without the need for laboratory testing. Hence it seems possible that as the mean level of resistance/resilience of a given flock improves, less loss in production could be expected on sheep production with TST application. Nevertheless, this needs to be monitored as selection progresses.

A confounding factor for evaluating the results of Farm 1 is that TST was not applied optimally, both as regards the long intervals between clinical evaluations (e.g. 12-32 days at the peak of the Haemonchus season, instead of 7 days, as recommended by Van Wyk \& Bath 2002), and the accuracy of FAMACHAC evaluation. Sensitivity/Specificity and Receiver Operating Characteristic curve analysis (Reynecke 2007) of data from Farm 1 indicated that the FAMACHAC evaluations on the farm were consistently about one FAMACHAC category too high. For instance, while all the sheep in FAMACHAC category 3 should have been treated, most were incorrectly classified as being in category 2 and were thus left untreated. Secondly, the recommendation is to evaluate sheep weekly at peak times of Haemonchus challenge, while, as shown in Table 2, the intervals varied from 17-21 days as from 18 December. Had the sheep been evaluated more often and had practically all the sheep with haematocrit values 
$<23 \%$ (i.e. in FAMACHAC categories $3-5$ ) been treated, it is unlikely that the levels of worm challenge would have risen to the levels observed (Reynecke 2007).

An important unknown from the trials is what the effect on the production of the FAMACHAC-treated animals would have been, had all the animals in Experiments 1 and 2 on Farm 1 not been dewormed when the Haemonchus challenge was at its worst. However, tactical treatment at that time should not have selected severely for drug resistance, granted that drugs with long residual action (such as the latest ivermectin and moxidectin formulations which have recently reached the market) were not used for deworming the sheep at that stage and that the sheep were not moved at the time of treatment to pastures with few worms in refugia. This surmise is supported by the fact that, as can be seen from the FECs recorded until May/June at the end of the worm season, reinfection did occur in both trials. This indicates that a tactical treatment at the peak of the worm season can, if necessary, be put to fruitful use in the field. Another strategy worth considering is to move the animals to "safe/clean" pastures before they become heavily infected, and to treat them only after they have been on the new pasture long enough for optimum levels of worm free-living stages to have accumulated in refugia on this new pasture largely to guard against selection for drug resistance (Molento, Van Wyk \& Coles 2004).

The expectation has frequently been expressed that leaving some animals in a flock undrenched would in time lead to progressively overwhelming accumulation of worms on the pasture from year to year. However, this has not occurred during the 6 years of application of TST on Farm 1, possibly because most of these free-living worm stages on pasture die during the cool, dry season (Horak \& Louw 1977; Horak 1978). However, there is certainly the possibility that a highly pathogenic, non-haematophagous worm species such as Oesophagostomum columbianum that is not diagnosed by the FAMACHAC system, can become more numerous and cause problems without the farmer being alerted to it, and this needs to be guarded against through regular monitoring.

\section{ACKNOWLEDGEMENTS}

These investigations were done with the support of the EU PARASOL project (EU FP6 call for applications), the National Wool Grower's Association and Cape Wools of South Africa. Without the enthusias- tic cooperation of and disregard of potential losses by the two farmers involved, this work could not have materialised. Prof. H.T. Groeneveld did the statistical evaluations and Mrs Rachel Coetzee was responsible for the data capture.

\section{REFERENCES}

BARGER, I.A. 1985. The statistical distribution of trichostrongylid nematodes in grazing lambs. International Journal for Parasitology, 15:645-649.

BATH, G.F., MALAN, F.S. \& VAN WYK, J.A. 1996. Skaap haarwurms: om te behandel of nie-dit is die vraag: Gebruik van die oogslymvlieskleur as leidraad. Proceedings of the South African Veterinary Association Biennial National Veterinary Congress, Cape Town, 1-4 October 1996: 264-268.

BATH, G.F. \& VAN WYK, J.A. 2001. Using the FAMACHAC system on commercial sheep farms in South Africa, in Proceedings, $5^{\text {th }}$ International Sheep Veterinary Congress, Stellenbosch, South Africa, 21-25 January 2001. Digital format.

BISSET, S.A., VAN WYK, J.A., BATH, G.F., MORRIS, C.A., STENSON, M.O. \& MALAN, F.S. 2001. Phenotypic and genetic relationships amongst FAMACHAC score, faecal egg counts and performance data in Merino sheep exposed to Haemonchus contortus infection in South Africa. Proceedings of the 5th International Sheep Veterinary Congress, Stellenbosch, South Africa, 21-25 January 2001. Digital format.

CARMICHAEL, I., VISSER, R., SCHNEIDER, D. \& SOLL, M. 1987. Haemonchus contortus resistance to ivermectin. Journal of the South African Veterinary Association, 58:93.

COTTLE, D.J. (Ed.). 1991. Australian Sheep and Wool Handbook. Melbourne: Inkata Press.

HORAK, I.G. 1978. Parasites of domestic and wild animals in South Africa. V. Helminths of sheep on dryland pasture on the Transvaal Highveld. Onderstepoort Journal of Veterinary Research, 45:1-6.

HORAK, I.G. \& LOUW, J.P. 1977. Parasites of domestic and wild animals in South Africa. IV. Helminths of sheep on irrigated pasture on the Transvaal Highveld. Onderstepoort Journal of Veterinary Research, 44:261-270.

KAPLAN, R.M., BURKE, J.M., TERRILL, T.H., MILLER, J.E., GETZ, W.R., MOBINI, S., VALENCIA, E., WILLIAMS, M.J., WILLIAMSON, L.H., LARSEN, M. \& VATTA, A.F. 2004. Validation of the FAMACHAC eye color chart for detecting clinical anemia in sheep and goats on farms in southern United States. Veterinary Parasitology, 123:105-120.

LEATHWICK, D.M., MILLER, C.M., ATKINSON, D.S., HAACK, N.A., ALEXANDER, R.A., OLIVER, A.M., WAGHORN, T.S., POTTER, J.F. \& SUTHERLAND, I.A. 2006a. New Zealand Veterinary Journal, 54:297-304.

LEATHWICK, D.M., WAGHORN, T.S., MILLER, C.M., ATKINSON, D.S., HAACK, N.A. \& OLIVER, A.M. 2006b. Selective and on-demand drenching of lambs: impact on parasite populations and performance of lambs. New Zealand Veterinary Journal, 54:305-312.

MALAN, F.S. \& VAN WYK, J.A. 1992. The packed cell volume and colour of the conjunctiva as aids for monitoring Haemonchus contortus infestation in sheep. Proceedings of the South African Veterinary Association Biennial National Veterinary Congress, Grahamstown, 7-10 September 1992:139. 
MALAN, F.S., VAN WYK, J.A. \& WESSELS, C.D. 2001. Clinical evaluation of anaemia in sheep: early trials. Onderstepoort Journal of Veterinary Research, 61:165-174.

MICHEL, J.F. 1969. The epidemiology and control of some nematode infections of grazing animals. Advances in Parasitology, 7:211-282.

MICHEL, J.F. 1976. The epidemiology and control of some nematode infections in grazing animals. Advances in Parasitology, 14:355-397.

MILLER, C.M., WAGHORN, T.S., LEATHWICK, D.M. \& GILMOUR, M.L. 2006. How repeatable is a faecal egg count reduction test? New Zealand Veterinary Journal, 54:323-328.

MOLENTO, M.B., VAN WYK, J.A. \& COLES, G.C. 2004. Sustainable worm management. Veterinary Record, 155:95-96.

MOLENTO, M.B., TASCA, C., GALLO, A., FERREIRA, M., BONONI, R. \& STECCA, E. 2004. Método FAMACHA como parâmetro clínico individual de infecção por Haemonchus contortus em pequenos ruminantes (FAMACHA guide as an individual clinical parameter for Haemonchus contortus infection in small ruminants). Ciências Rural, Santa Maria, 34: 1139-1145.

REINECKE, R.K. 1973. The larval anthelmintic test in ruminants. Republic of South Africa, Department of Agricultural Technical Services (Technical Communication, no.106).

REYNECKE, D.P. 2007. Software-based decision-support: a basis for the development of a predictive system for sustainable management of haemonchosis in small ruminants. Ph.D. thesis, University of Pretoria.

RHODES, A.P., LEATHWICK, D.M., POMROY, W.E., WEST, D.M., JACKSON, R., LAWRENCE, K., MOFFAT, J. \& WAGHORN, T.S. 2006. A profile of anthelmintic resistance and parasite control practices in New Zealand-results from a 2005 survey. Proceedings of the New Zealand Society of Animal Production, 66:14-19.

SOTOMAIOR, C., MILCZEWSKI, V., MORAIS, F.R. \& SCHWARTZ, M.G. 2003: Evaluation of FAMACHAC system: accuracy of anaemia estimation and use of the method on commercial sheep flocks. Merida, Yucatan, Mexico; Proceedings of the 5th International Seminar In Animal Parasitology, 1-3 October 2003: 61-65.

VAN WYK, J.A., GERBER, H.M. \& ALVES, REGINA M.R. 1982. Slight resistance to the residual effect of closantel in a field strain of Haemonchus contortus which showed an increased resistance after one selection in the laboratory. Onderstepoort Journal of Veterinary Research, 49:257-261.

VAN WYK, J.A., MALAN, F.S., GERBER, H.M. \& ALVES, R.M.R. 1987. Two field strains of Haemonchus contortus resistant to rafoxanide. Onderstepoort Journal of Veterinary Research, 54:143-146.

VAN WYK, J.A. \& MALAN, F.S. 1988. Resistance of field strains of Haemonchus contortus to ivermectin, closantel, rafoxanide and the benzimidazoles in South Africa. Veterinary Record, 123:226-228.
VAN WYK, J.A. \& VAN SCHALKWYK, P.C. 1990. A novel approach to the control of anthelmintic resistance in sheep. Veterinary Parasitology, 35:61-69.

VAN WYK, J.A., MALAN, F.S. \& BATH, G.F. 1997a. Rampant anthelmintic resistance in sheep in South Africa-what are the options? in Managing anthelmintic resistance in endoparasites, edited by J.A. van Wyk \& P.C. van Schalkwyk. Proceedings of the Workshop at the 16th International Conference of the World Association for the Advancement of Veterinary Parasitology, Sun City, South Africa: 51-60.

VAN WYK, J.A., MALAN, F.S. \& RANDLES, J.L. 1997b. How long before resistance makes it impossible to control some field strains of Haemonchus contortus in South Africa with any of the anthelmintics? Veterinary Parasitology, 70:111122.

VAN WYK J.A., STENSON, M.O., VAN DER MERWE, J.S., VORSTER, R.J. \& VILJOEN, P.G. 1999. Anthelmintic resistance in South Africa: surveys indicate an extremely serious situation in sheep and goat farming. Onderstepoort Journal of Veterinary Research, 66:273-284.

VAN WYK, J.A. 2001. Refugia-overlooked as perhaps the most potent factor concerning the development of anthelmintic resistance. Onderstepoort Journal of Veterinary Research, 68: 55-67.

VAN WYK, J.A., BATH, G.F., GROENEVELD, H.T., STENSON, M.O. \& MALAN, F.S. 2001a. Extensive testing of the FAMACHAC system for accuracy of clinical evaluation of anaemia caused by ovine haemonchosis. Proceedings of the 5th International Sheep Veterinary Congress, Stellenbosch, South Africa, 21-25 January 2001. Digital format.

VAN WYK, J.A., VAN WIJK, E.F., STENSON, M.O. \& BARNARD, S.H. 2001b. Anthelmintic resistance reversion by dilution with a susceptible strain of Haemonchus contortus in the field: preliminary report. Proceedings of the 5th International Sheep Veterinary Congress, Stellenbosch, South Africa, 2125 January 2001. Digital format.

VAN WYK, J.A. \& BATH, G.F. 2002. The FAMACHAC system for managing haemonchosis in sheep and goats by clinically identifying individual animals for treatment. Veterinary Research, 33:509-529.

VAN WYK, J.A. 2003. Think refugia or lose the battle against drug resistance, in Proceedings of the 5th International Seminar in Animal Parasitology, Merida, Yucatan Mexico, 1-3 October 2003: 39-47.

VAN WYK, J.A. 2006. Face facts: drenching with anthelmintics for worm control selects for worm resistance-and no excuses! Proceedings of the New Zealand Society of Animal Production: 4-13.

VAN WYK, J.A., HOSTE, H., KAPLAN, R.M. \& BESIER, R.B. 2006. Targeted selective treatment for worm managementhow do we sell rational programs to farmers? Veterinary Parasitology, 139:336-346.

WALLER, P.J. 1997. Anthelmintic resistance. Veterinary Parasitolology, 72:391-405. 